\title{
Teología y belleza: en busca de la unidad perdida
}

\author{
JAVIER SÁNCHEZ CAÑIZARES \\ Universidad de Navarra (España) \\ js.canizares@unav.es
}

\begin{abstract}
Resumen
La modernidad se caracteriza por una epistemología que ha conducido a la separación de los saberes. Como consecuencia, tanto la teología protestante como la católica han sufrido la falta de una perspectiva unitaria en su razonar sobre Dios. La cultura postmoderna, aceptando la fragmentariedad, presenta una nueva sensibilidad epistemológica que abre posibilidades prometedoras para el redescubrimiento de la trascendencia. Entre ellas, la dialogicidad intrínseca de la Creación apunta a la vía de la belleza como camino privilegiado que la teología ha de explorar en un sentido descendente $\mathrm{y}$, especialmente, ascendente.
\end{abstract}

Palabras claves: teología, belleza, unidad del conocimiento.

\section{Theology and Beauty: Searching for the lost union}

\begin{abstract}
Modernity is epistemologically characterized by the division of knowledge. As a result, Protestant and Catholic Theology have both lacked a unifying vision in their reasoning about God. The acceptance of fragmentation in postmodern culture offers a new epistemological sensibility, which opens up inspiring possibilities for the rediscovery of transcendence. Among these possibilities, the intrinsically dialogical character of Creation aims at the via of beauty as a privileged path that Theology should explore in a descending and, especially, an ascending way.
\end{abstract}

Key words: Theology, beauty, unity of knowledge.

Doctor en Ciencias Físicas por la Universidad Autónoma de Madrid y doctor en Teología por la Pontificia Università della Santa Croce. Fue ordenado sacerdote en 2005. Actualmente, es Profesor de Teología Moral en la Facultad de Teología de la Universidad de Navarra. Es miembro del Grupo de Investigación sobre Ciencia, Razón y Fe (CRYF) y pertenece al grupo internacional de investigación en Teología Moral Hypsosis. Además de participar en varios proyectos de investigación de la Unión Europea y en diversos congresos, ha publicado numerosos artículos científicos en física, filosofía y teología. Entre sus publicaciones destacan los libros La revelación de Dios en la creación: las referencias patrísticas a Hch 17,16-34 (2006) y Moral humana y Misterio Pascual. La esperanza del Hijo (2011). 


\section{El problema epistemológico moderno}

Es indudable que la modernidad lleva bastantes años en crisis, si bien ninguno de sus actuales críticos, tanto a nivel histórico como conceptual, dejaría de señalar la larga serie de avances que, a partir de la misma, han marcado decisivamente la historia del género humano ${ }^{1}$. Querría iniciar esta reflexión centrándome en el cambio producido en los espíritus modernos con relación al método de pensamiento: si el Medioevo venía caracterizado metodológicamente por una cierta unidad del saber (o de los saberes), que se podría calificar de sapiencial, el cambio de coordenadas moderno lleva al espíritu de método, que da primacía a la herramienta analítica frente a la unidad ingenua de la síntesis.

Esta característica general de los espíritus ha tenido como fruto la progresiva pérdida de la visión unitaria, tanto a nivel vital como intelectual. Como un ejemplo de lo que decimos, aparecería en los últimos siglos el drama de la separación entre fe y razón ${ }^{2}$. Si en los albores de la modernidad encontramos todavía pensadores del todo como un Leibniz, o incluso un Pascal, con su aguda distinción entre el esprit de géométrie et esprit de finesse, la tendencia histórica resulta imparable, hasta llegar a los excesos ochocentescos de una separación total entre tradicionalismo e iluminismo o de un positivismo absoluto ${ }^{3}$. Cobra así sentido la queja histórica de von Balthasar: «Nos hemos convertido en analistas del mundo y también del alma, y ya no tenemos capacidad de captar la totalidad $\rangle^{4}$.

Como paladín de la modernidad se presentaría el cientificismo positivista, con sus pretensiones de dominio puramente racional, gracias a un método neutral, de verificación empírica, que rechaza (evidentemente a priori) todo lo que caiga fuera de su alcance. Hoy día, a pesar de los retoques epistemológicos de Karl Popper, ningún profesional serio de la ciencia experimental es positivista, siendo cada vez

\footnotetext{
1 Así, el nacimiento de la ciencia o el comienzo de los estados modernos, como dos ejemplos paradigmáticos.

2 A este respecto, resultan iluminadores los nn. 45-48 de la encíclica Fides et ratio de Juan Pablo II.

3 Es muy esclarecedor el análisis sobre A. Comte y su pretensión de una nueva religión positivista universal que se hace en H. DE LUBAC: Le drame de l'bumanisme athée. Cerf, Paris 2000, 141ss., en especial, 238: Le sacerdoce de savants. En general, todo el libro se mueve en la óptica de la imposibilidad de un verdadero humanismo sin Dios.

4 «Siamo divenuti analisti del mondo e anche dell'anima e non siamo più in grado di cogliere la totalità», H. U. VON BALTHASAR: Gloria: una estética teológica. Jaca Book, Milano 1971, 16-17.
} 
más consciente de las influencias de todo tipo -históricas, sociales, económicas...- que recibe la ciencia a la que contribuye ${ }^{5}$. Y es que, en el fondo, la realidad, no es una realidad muerta, susceptible de objetivación y experimentación ad infinitum, como exigía el método científico extremo, que ha terminado haciendo necrofagia de la misma para poder desarrollarse ${ }^{6}$.

\subsection{Influencia en la teología}

La teología no ha quedado inmune ante este proceso disgregador. Encontramos el primer golpe serio en la reacción luterana -quizás en algunos aspectos justificada, pero de consecuencias devastantes- contra la simplificación estética de la metafísica cristiana de matriz neoplatónica, al referirse al misterio pascual de Cristo. La crítica ante lo que se consideraba una aproximación lenta, cada vez más ontológica y éticomística, a la divinidad ${ }^{7}$, llevará consigo, como contraposición a partir de entonces, el sello de la oposición dialéctica theologia crucis / theologia gloriae.

En el ámbito protestante, los intentos de recuperar la unidad de la teología mediante el pulchrum han partido, desde entonces, con un problema de fondo: en último término la belleza sería predicamental, no trascendental; no pertenecería a Dios en un sentido originario, estando al servicio del anuncio. La palabra estética sería ocasión para el (auténtico) evento de la palabra. Con Karl Barth, se intenta dar un paso adelante, abandonando la nuda pistis para llegar a una gnosis inherente a la misma $\mathrm{fe}^{8}$, pues la Revelación llevaría consigo la forma y belleza propias; por lo que no habría necesidad de buscar forma y belleza fuera de la misma Revelación.

En el ámbito católico la historia no es mucho más feliz, pues aparece el riesgo de caer del otro lado de la balanza. Encontramos las propuestas de un idealismo y romanticismo secularizados, con el pulchrum como objeto específico de una ciencia particular. Mientras, el drama de la separación sigue su curso como señala paradigmáticamente la letal formulación de Lessing: la teología tendría que ver con las «verdades históricas

A la hora de mostrar las insuficiencias generales del positivismo o neopositivismo en el s. XX, es obligada la referencia a K. Gödel y sus teoremas de incompletitud, desde el punto de vista lógico-matemático, y a T. Kuhn y su estudio de la estructura de las revoluciones científicas, desde el punto de vista histórico-sociológico.

6 Resultan especialmente adecuadas las reflexiones sobre el concepto de experiencia impuesto por el cientificismo que se encuentran en J. RATZINGER: Elementi di Teologia Fondamentale. Morcelliana, Brescia 1986, 88.

7 Cfr. H. U. vON BALTHASAR: Gloria: una estética teológica, 36.

8 Ibíd., 43. 
contingentes», mientras la filosofía se debería ocupar de las «verdades necesarias de la razónı". Se intenta un apologetismo estético por parte de Chateaubriand; basado en criterios intramundanos con Herder, Gügler... Hay entusiasmo y se busca englobar la totalidad visible, sí, pero ¿quizás con cierto regusto pelagiano? Son problemas derivados del monismo filosófico y de una visión de la naturaleza surcada por una idea de sacramentalidad universal ${ }^{0}$. Con Scheeben aparece decididamente mantenida la fundamental distinción naturaleza / gracia, y se presenta una relación esponsal entre la fe y la razón, siendo la naturaleza in-formada (como forma suprema de cumplimiento) por medio de la gracia, fusionadas ambas en un único ser, siguiendo el sentir patrístico. No obstante, a pesar de estos esfuerzos, queda aún por descifrar el mysterium iniquitatis, que lleva al mysterium crucis en la historia de la salvación o, dicho de otra manera, englobar la teología del pecado original en una síntesis teológica más lograda.

\subsection{Modernidad frente a Postmodernidad}

Volviendo a la situación general, después del fracaso positivista -incluso en su versión más contemporánea de salvación mediante la técnica o el arte de consumo- y el de la propia modernidad - incapaz de redimir al hombre de la trágica tríada muerte, dolor, culpa-, una vez completado el recorrido de secularización, autonomía, inmanentismo, profanización que parece recorrerse hasta llegar al pensamiento y a la cultura actuales, ¿qué podemos encontrar con el nuevo cambio de paradigma que trae consigo la posmodernidad?

No hay que olvidar que en el paradigma anterior, de acuerdo con la tendencia racionalista dominante, el acceso a Dios por parte del hombre se ha hecho a través del principio de razón (causa) suficiente (nunca podría ser necesaria); sin embargo, tampoco concedido Dios pueden ser deducidos el hombre o el mundo como efectos necesarios. La pregunta que surge con fuerza en el creyente posmoderno es acerca de la «lógica» que deberíamos seguir en las relaciones entre Dios, el hombre y el mundo; en el acceso a Dios. De hecho, la recuperación de la trascendencia olvidada por la cultura moderna no es inmediata: «El fracaso de la pietas mundi [sustitución Dios-ciencia, religión-técnica], sin embargo, ha puesto en movimiento innumerables procesos de sustitución, y no está claro que la nueva aceptación del pensamiento religioso se dé con referencia a la trascendencia. De hecho, faltan todavía

\footnotetext{
$9 \quad$ Ibíd., 63.

$10 \quad$ Ibíd., 89.
} 
elementos para esta apertura y la solución más fácil e inmediata se busca (la casuística sería infinita) en el más acás $\rangle^{11}$. No obstante, parece que en la posmodernidad, con sus contrastes y su intrínseca relacionalidad, se abren nuevos espacios de diálogo con los que podríamos llamar «ateos de buena voluntad», en quienes aún queda un residuo de apertura a lo trascendente $e^{12}$.

El fracaso de la pretendida lógica total de la modernidad permite una revalorización de la experiencia personal, como hecho subjetivo-objetivo digno del mayor respeto y que, en el fondo, a pesar de la crítica deconstructivista, acaba por ir en busca de un fundamento. Así, la experiencia de la alteridad y de la pertenencia a un entramado de relaciones, puede y debe ser trampolín para una razón acompañada que busca a Dios ${ }^{13}$.

\section{El hombre y la Creación}

Antes de pasar a analizar el papel que puede jugar la belleza, merece la pena detener la reflexión en las relaciones del hombre con la naturaleza creada, como lugar privilegiado donde percibir el cambio de tendencia. Es cierto que la liberación de la idea de progreso indefinido mediante el dominio absoluto de la naturaleza ha dejado paso en muchos casos a lo que podríamos llamar un ecologismo extremo, con tintes

11 «La delusione della pietas mundi, però, ha messo in moto innumerevoli processi di sostituzione, e non è detto che la nuova accettazione del pensiero religioso si dia in riferimento alla trascendenza. Di fatto, mancano ancora elementi per questa apertura, e la soluzione più facile e immediata la si cerca (la casistica sarebbe infinita) nell'al di qua», J. M. Galván: "L'arte come via di evangelizzazione", en H. Fitte (ed.), Fermenti nella teologia alle soglie del terzo millennio: Atti del III Simposio internazionale della Facoltà di teologia, Roma, 12-14 marzo 1997, Libreria Editrice Vaticana, Città del Vaticano 1998, 290.

12 Puede pensarse en este caso en intelectuales como A. Camus. «La última frase de su ensayo: 'Es preciso imaginarse a Sísifo dichoso' resume su pensamiento. Sísifo tenía que transportar un enorme bloque de piedra a la cumbre de la montaña. Cada vez que el desdichado llegaba a la cima, el bloque se le escapaba de las manos y rodaba hasta abajo. Sísifo lo recogía y volvía a comenzar sus esfuerzos. Esta lucha indefinidamente recomenzada, en una eterna rotación de pesadilla, simboliza el descubrimiento del absurdo omnipresente en el universo. Pues bien, a este Sísifo es preciso imaginárselo 'dichoso'», C. MOELLER: Literatura del siglo XX y cristianismo. Gredos, Madrid 1955, 69. Pero al mismo tiempo: «¿Cómo no amar a un hombre que, en medio de nuestro mundo de la hora veinticinco, de náusea, de 'desprecio del hombre' ha escrito estas líneas: 'En los hombres hay más motivos de admiración que de desprecio’», Ibíd., 123.

13 Este concepto de «razón acompañada», como herramienta digna de todo hombre que se desarrolla en una comunidad surcada de relaciones interpersonales, parece estar en el centro de toda la encíclica Fides et ratio. 
panteístas en el mejor de los $\operatorname{casos}^{14}$. A pesar de todo, parece que existe un retorno del pensamiento cristiano sobre la cuestión de la Creación y su propio lugar teológico dentro del cristianismo. Las misteriosas palabras de $\mathrm{R} m$ 8, 20-22 no dejan lugar a dudas sobre la importancia de lo creado en la historia de la salvación y, en cierta manera, apuntan a la conexión de la misma con el estado preternatural y, en definitiva, con su sentido último en Cristo; por lo que ha de jugar un papel esencial en la vida de cada hombre, como lugar de encuentro con el Redentor ${ }^{15}$. Si el hombre es la única criatura que Dios ha querido por sí misma, posee la apasionante tarea de corresponder, como imagen y semejanza, al don intratrinitario de las Personas mediante el don sincero de $\mathrm{si}^{16}$; haciendo «transparente» la Creación (que espera la liberación de los hijos de Dios) al poder de Dios, para poderla incluir consigo - como materia deificada- en la comunión con la Trinidad. El mundo material alcanza su pleno sentido con la presencia de la persona humana, que no puede considerarse como «extrínseca» a Dios ${ }^{17}$. La Creación aparece, fundamental, si bien no únicamente, como creación de personas. En ella, si el hombre no hubiese roto el diálogo inicial, la condición espaciotemporal no sería experimentada como límite: el espacio-tiempo estaría protegido por Dios, siendo de por sí dialógico como lo será en la Jerusalén celeste.

A pesar de la presencia real y misteriosa de la culpa original, la temporalidad inaugurada con ella será la de la sucesividad, que permite al hombre ser perdonado por parte de Dios y, al mismo tiempo, tener que entender su propia unidad en modo dinámico ${ }^{18}$. El tiempo adquiere

14 Se puede ver al respecto el análisis de J. RATZINGER: Creazione e peccato. Paoline Roma 1986, 30-34.

15 Cfr., por ejemplo, JUAN PABLO II: Dominum et Vivificantem, n. 50. En clave moral, el hombre creado estaría ya predispuesto a la filiación en Cristo, cfr. R. TREMBLAY: Radicati e fondati nel Figlio. Contributi per una morale di tipo filiale. Dehoniane, Roma 1997, 47-52; ibíd., Vous, lumière du monde. La vie morale des chrétiens: Dieu parmi les hommes. Fides, Québec 2003, 143-146; ibíd., "Dalla persona umana capax Dei in Filio alla persona filiale", en R. Tremblay y S. Zamboni (eds.), Figli nel Figlio. Una teologia morale fondamentale, Edizione Dehoniane, Bologna 2008, 165-180.

16 Cfr. Concilio Vaticano II: Gaudium et spes, n. 24.

17 Cfr. Santo Tomás de Aquino: De Potentia, 9, 9.

18 «Una percezione di dove sono e di quel che sono (...) non posso averla se non a condizione di sapere come sono arrivato dove sono e come sono diventato quel che sono. L'immagine che ho di me stesso è quella di un essere che si muove e diviene, fenomeno che, per sua natura, non può essere instantaneo. Ciò significa non solo che ho bisogno di tempo e di molte traversie per sceverare ciò che, nel mio carattere, nel mio temperamento e nei miei desideri, è relativamente fisso e stabile da ciò che è, invece, variabile e mutevole; ma anche che, como essere che si muove e diviene, io posso conoscere me stesso solo per il tramite dei miei progressi e dei miei regressi, delle 
también así una dimensión reveladora para el hombre pues, por una parte, si Dios no fuera, la historia sería trascendente para cada hombre particular (aunque en sí fuese inmanente); por otra, se experimenta la creatividad en la temporalidad significativamente como vida nueva, por lo que ésta no se puede enviar continuamente a un tiempo indeterminado, lo que apunta a una vida no medida por el tiempo ${ }^{19}$, o incluso a la posibilidad de irrupción en él de la eternidad.

Una mayor atención a la materialidad del mundo creado reviste además una importancia decisiva para una correcta teología de las religiones y para el diálogo interreligioso, fenómeno en sí ineludible en el contexto globalizado actual ${ }^{20}$. Además, y es lo que nos interesa más aquí, permite un acceso a la trascendencia a partir de la experiencia personal de la belleza - experiencia verdaderamente metafísica, por la unidad y circularidad de los trascendentales ${ }^{21}$, que puede enlazarse con la experiencia de la fe-, más adecuada en el contexto posmoderno.

\section{Teología y belleza}

\section{1. ¿Una teología estética o una estética teológica?}

Desde el punto de vista de la nueva evangelización, a pesar de los conocidos intentos de von Balthasar, no resulta aún en mi opinión practicable una teología estética de divulgación, cuyo mensaje llegue al gran público. Por eso «el gran desafío se encuentra en la vía ascendente: se trata ahora, para llegar a un verdadero diálogo de la teología con el

mie vittorie e delle mie sconfitte. La mia immagine di me stesso necessariamente ha uno spessore temporale e una struttura narrativa», C. TAYLOR: Radici dello'io. La costruzione dell'identità moderna. Feltrinelli, Milano 1993, 71.

19 Cfr. J. M. GALVÁN: “Arte e razionalità contemporánea”, en S. Grossi-Gondi (ed.), La conoscenza estetica, Leonardo da Vinci, Roma 2000, 15-22.

20 «Tutto l'universo raccoglie in sé un messagio estetico e teologico che l'uomo deve decifrare», G. RAVASI: "Bibbia e cultura I: Bibbia e arte", en P. Rossano, G. Ravasi, A. Girlanda (eds.), Nuovo Dizionario di Teologia Biblica. San Paolo, Cinisello Balsamo 1988, 169-192.

21 No hay que olvidar, por ejemplo, que «para un griego, belleza y bondad moral son términos casi equivalentes; la ética y la estética se encuentran indisolublemente ligadas (...) 'Lo bello es la virtud' (Diógenes Laercio), pero con un matiz de nobleza y excelencia (...) El kalokagathós no es sólo el hombre honesto que une la belleza y la bondad, sino que es además el hombre de honor. Su virtud, fundada en el equilibrio y la medida, tiene un brillo especial y se despliega en acciones meritorias que suscitan la alabanza de todos. Esta moral del honor queda asumida por el cristianismo», C. SPICQ: Teología Moral del Nuevo Testamento, vol. I, Eunsa, Pamplona 1970, 139-141. 
mundo, de descubrir la dimensión crística presente en el actuar y en la creación de belleza del hombre» ${ }^{22}$.

La vía de una estética teológica resulta más comprensible para el hombre actual, más acostumbrado a una construcción intelectual que empiece desde abajo (es decir, desde el fenómeno, la percepción personal, diríamos casi el sentimiento); mas ello es posible gracias a la belleza presente en todo lo creado. Es cierto que permanece la dificultad inherente a la tensión escatológica, pues la dimensión salvífica de la historia, de cada historia en su concreción espacio-temporal no se puede captar en plenitud; pero la verdadera obra de arte debe actuar como «puente» con ese estado de justicia originaria cuyo recuerdo jamás se ha apagado en el hombre ${ }^{23}$. Si se trata de verdadero arte - fundado en la Creación-, el mismo habrá de ser ya crístico, en el sentido de poner en relación calcedoniana (inseparabiliter, indivise, inconfuse, immutabiliter) la belleza de Dios con la belleza creada, haciendo posible la conexión del momento presente con el Paraíso. La obra de arte permite la experiencia del don (en la inspiración del artista o en el que contempla la obra) y, en definitiva, el paso a lo trascendente ${ }^{24}$.

Esto, evidentemente, no supone olvidar el riesgo permanente que existe de identificar la estética divina y la del mundo. El abuso entonces consiste en someter y subordinar simplemente a las leyes de la metafísica

22 «La grande sfida si trova nella via ascendente: si tratta adesso, per arrivare a un vero dialogo della teologia con il mondo, di scoprire la dimensione cristica presente nell'agire e nel fare bello dell'uomo», J. M. GALVÁN: "Arte e razionalità contemporánea", 21.

23 En mi opinión, una de las obras literarias en que se aprecia esto de modo más nítido es Four Quartets de T. S. Eliot.

24 Así, «el arte, incluso más allá de sus expresiones más típicamente religiosas, cuando es auténtico, tiene una íntima afinidad con el mundo de la fe, de modo que, hasta en las condiciones de mayor desapego de la cultura respecto a la Iglesia, precisamente el arte continúa siendo una especie de puente tendido hacia la experiencia religiosa. En cuanto búsqueda de la belleza, fruto de una imaginación que va más allá de lo cotidiano, es por su naturaleza una especie de llamada al Misterio. Incluso cuando escudriña las profundidades más oscuras del alma o los aspectos más desconcertantes del mal, el artista se hace de algún modo voz de la expectativa universal de redención», JUAN PABLO II: Carta a los artistas, n. 10. También es ilustrativo el siguiente comentario aplicado a la narrativa: «Los soportes o cimientos [de la infraestructura conceptual de la ficción literaria en su dimensión apologista] son: la voluntad sobrenatural del ser humano, la peculiaridad de su quehacer artístico — que siempre se nutre de experiencias del autor-, el acervo intelectual que contiene la narración más sencilla (es decir, su capacidad de ayudar a aprender) y el potencial transformador o catárquico que dichas narraciones poseen - transformación que siempre está mediada por la libertad humana en cuanto árbitro de la aplicabilidad de un mensaje a la propia vida», J. M. ODERO: "Apologías y literatura", en C. Izquierdo (ed.), Teología Fundamental. Temas y propuestas para el nuevo milenio, Desclée de Brouwer, Bilbao 1999, 536-537. 
y de la ética (privada, social o sociológica), o también de la estética intramundana, la forma de la revelación divina, en lugar de respetar la soberanía manifestada claramente en la obra de Dios. Esto sucede en la estética tanto más frecuente y fácilmente porque la estética mundana aparecería como más fascinante que la metafísica y la ética mundanas, permanentemente problemáticas ${ }^{25}$.

\subsection{Las posibilidades de la belleza}

Por ello, encontramos aún en von Balthasar la siguiente clave interpretativa del camino a recorrer: «Toda belleza creatural tiene siempre dos dimensiones, que se pueden designar como extensión horizontal y profundidad vertical, son (para decirlo al modo escolástico) forma (proporción de las partes en la configuración compleja) y al mismo tiempo lumen (refulgir que emana de la profundidad del ser); una y otra son inseparables entre sí, aunque sus relaciones pueden variar infinitamente ${ }^{26}$. Percepción de la primera, que media para que permitamos ser raptados por la segunda ${ }^{27}$.

Nos encontramos aquí con una teología estética que nos señala la vía de la teología fundamental a la dogmática como crecimiento en la fe: «La evidencia en la percepción de los hechos de la Revelación, alcanzada inicialmente con la luz de la gracia — una evidencia que era ya ella misma rapto- se deja desarrollar ulteriormente en conformidad con las propias leyes ${ }^{28}$. Mediante la percepción como momento de la teología fundamental y el rapto como momento dogmático, se realizaría el admirabile commercium de nuestra divinización. Pero esta lectura en un contexto de gracia, nos permite ahondar en las características que debe tener un acceso «desde

\footnotetext{
25 Cfr. H. U. VON BALTHASAR: Gloria: una estética teológica, 27.

26 «Ogni bello creaturale ha sempre due dimensioni, che si possono designare come estensione orizzontale e profondità verticale; esse sono (per dirla con la scolastica) forma (proporzione delle parti nella configurazione complessiva) e al tempo stesso lumen (il rifulgere che promana dalle profondità dell'essere); l'una e l'altro sono inseparabili tra di loro, anche se i loro rapporti possono variare all'infinito», H. U. vON BALTHASAR: "Il concetto di bello in Teologia", Seminarium, n 3 (1981), 474.

27 Como ejemplo, véase el Prefacio I de Navidad: «Quia per incarnati Verbi mysterium nova mentis nostrae oculis lux tuae claritatis infulsit: ut dum visibiliter Deum cognoscimus, per bunc in invisibilium amorem rapiamun (La cursiva es mía); cfr. H. U. VON BALTHASAR: Gloria: una estética teológica, 105.

28 «L'evidenza nella percezione dei fatti della rivelazione, raggiunta inizialmente nella luce della grazia - un'evidenza che era già essa stessa rapimento- si lascia ulteriormente sviluppare in conformità alle proprie leggi», Ibíd., 111.
} 
abajo», desde la belleza creatural. La misma teología bíblica conoce bien dicho proceso ${ }^{29}$.

El lenguaje de la belleza, con su proporción, su integridad y su luminosidad, da cabida, sobre todo, a la simbología, signo de lo verdadero, que mantiene la unidad del fenómeno originario: cuerpo / palabra; interioridad / comunicación, frente a los malentendidos de la alegoría (que es un decir diversamente) ${ }^{30}$. La belleza creatural mantiene: (i) la conexión con la realidad sensible; (iv) la génesis de la novedad, mediante la creación-invención de nuevos nexos, que permiten el crecimiento en humanidad verdadera. Así, aun cuando la obra de arte no sea en sí misma gracia, por su carácter simbólico representativo ${ }^{31}$ - que señala además la estructura dialógica de la verdad-, permite captar anagógicamente la espiritualidad de lo sensible. Cuando esta experiencia viene guiada por el Espíritu, permitirá el acceso -a través de los atributos divinos, que reclaman siempre un sujeto personal-a la intimidad de Dios; mas, en el peor de los casos, será cauce de la apertura antropológica a la trascendencia. Es, en último término, la doble dimensión del símbolo (lo que requiere cierta disposición minima de la materia y de la persona) aquello que posibilita la experiencia de la trascendencia.

Pero, además, gracias a la integración de planos de lo real en una unidad también real que permite el símbolo cuando es verdadero, la obra de arte recupera la unidad de contrarios en el contraste artístico, a diferencia de las antinomias de la contrariedad que se encuentran cuando el enfoque es exclusivamente racional o racionalista. El arte permite expresar mejor la comunión, la unidad en la diversidad orgánica que da cabida a la finalidad. De alguna manera, se escucha aquí el eco del pensamiento de Nicolás de Cusa, con la centralidad atribuida a la unidad de los contrarios, que se hace especialmente acuciante en el mundo posmoderno.

Finalmente, mediante el valor dialógico de la materia y su capacidad simbólica, la obra de arte logra una armonía interna que, en el caso de la narrativa - literaria, musical, cinematográfica一, ofrece además la visión

\footnotetext{
29 «Alcuni di questi concetti legati alla belleza riflettono l'influsso dell'ambiente ellenistico in cui maturarono e da cui deriva pure l'ammirazione per l'alternasi armonioso degli elementi costitutivi dell'universo (...). Ma fundamentalmente essi si richiamano pure alla traditione biblica più antica, la quale, attendendo più al dinamismo e alla a potenza delle cose che ai loro colori, aveva sempre intravisto del mondo e nei suoi elementi un motivo per cantare la grandeza, la potenza e la magnificenza del loro Creatore», A. Sisti: "Bellezza", en P. Rossano, G. Ravasi, A. Girlanda (eds.), Nuovo Dizionario di Teologia Biblica. San Paolo, Cinisello Balsamo 1988, 163.

30 Cf. H. U. vON BALTHASAR, Gloria: una estética teológica, 12-13.

31 Fundado, en definitiva, en la realidad de la Creación en Cristo.
} 
unitaria de una sucesividad. Se puede mostrar así el resultado sorprendente de un proceso inicial aparentemente irrelevante, evocando la superación del tiempo y de la misma historia. En definitiva, respetándose la autonomía de la obra de arte, unum y pulchrum, sin necesidad de que haya un contenido explícitamente religioso, se da la apertura al misterio de la trascendencia ${ }^{32}$. Se descubren los nexos profundos del mundo real y del hombre cotidiano quien, en definitiva, no puede hablar una palabra humana sin referirse a los atributos divinos.

Sumario: 1. El problema epistemológico moderno; 1.1. Influencia en la teología; 1.2. Modernidad frente a Postmodernidad; 2. El hombre y la creación; 3. Teología y belleza; 3.1. ¿Una teología estética o una estética teológica?; 3.2. Las posibilidades de la belleza.

32 Así, se puede decir que «el potencial literario de un texto reside en su falta de interpretación, es decir, la calidad literaria de una narración radica en no contener explícitamente dentro de ella una cierta tesis que intente ser difundida como verdadera; y, más concretamente, dicho potencial literario supone el hecho de que el relato no esté intrínsecamente subordinado a convencer al lector acerca de dicha tesis. El texto literario ha de tener primariamente una calidad estrictamente literaria, que reside en su belleza, si bien dicha belleza se mostrará últimamente como una dimensión que resulta inseparable de la verdad (sobre todo, inseparable de la verdad acerca del hombre). La esclavitud de la ficción a cualquier tipo de didactismo - aun cuando este se halle ingeniosa y arteramente camuflado- arruina sin duda su calidad artística», J. M. ODERO: "Apologías y literatura", 522-523. Pero esto no quiere decir que se quede en la pura contemplación: «La ficción literaria de alta calidad posee la capacidad de emocionar al sujeto - estimulando su amor por lo bello, bueno y verdadero que hay en Dios- y de impulsarle hacia un tipo de acción acorde con el amor o el odio por alguna realidad concreta de su existencia cara a Dios, amor u odio que la narración ha promovido», ibíd., 527. 